\title{
Determinants of Adverse Perinatal Outcomes Among Mothers Who Gave Birth at Selected Governmental Hospitals in Southwest Ethiopia
}

\author{
Terefe Keto \\ Mizan-Aman Health Science College \\ Isrel Darekiyab \\ Mizan-Aman Health Science College \\ Melese Tebeka ( $\sim$ melesetebeka46@gmail.com ) \\ Mizan-Aman Health Science College
}

\section{Research Article}

Keywords: Perinatal outcomes, Determinates, Southwest, Ethiopia

Posted Date: November 3rd, 2021

DOI: https://doi.org/10.21203/rs.3.rs-1022059/v1

License: (c) This work is licensed under a Creative Commons Attribution 4.0 International License.

Read Full License 


\section{DETERMINANTS OF ADVERSE PREINATAL OUT COMES AMONG MOTHERS WHO GAVE BIRTH AT SELECTED GOVERNMENTAL HOSPITALS IN SOUTHWEST ETHIOPIA}

ISRAELDEREKIYAB (MPH) ${ }^{1}$

isrelderekiyab@gmail.com

TEREFE KETO (Bsc) ${ }^{1}$

tereedzaza@gmail.com

MELESE TEBEKA (MPH) ${ }^{1 *}$

meleseaddis123@gmail.com

1 Department of Public Health, Mizan-Aman Health Science College, Southwest Ethiopia E-mail: acohs@ethionet.et

Corresponding author MELESE TEBEKA

meleseaddis123@gmail.com 


\begin{abstract}
Background: Perinatal outcomes refer to life events that occur to the newborn baby from the age of viability (28 weeks) to the first week of life. The transition of fetus immersed in the amniotic fluid to life outside the womb is not always smooth and can result in adverse events to the mother or the baby. Adverse perinatal outcome is the major challenge both in low and middle-income countries. Globally, adverse birth outcomes commonly preterm birth, low birth weight, stillbirth and neonatal death are significant problems. Neonatal morbidities and mortalities are one of the most common contributing factorsfor11.8 million deaths. Despite ample strategies and interventions, prevention of adverse birth outcomes has remained largely unaddressed.
\end{abstract}

Objectives: the main objectives of this study is to assess the determinants of adverse preinatal outcome among mothers who gave birth at selected governmental hospital in southwest Ethiopia Methods: This study was done using data from three selected governmental Hospital found in southwest Ethiopia. Facility based unmatched case control study design was carried out from May 5 to June15, 2021.The data was collected through interview by considering COVID-19 prevention protocol.Total of 310 study subject was included in the study. An individual was selected through consecutive sampling techniques. Data was entered using EpiData and analysed by using SPSS version 23. A threshold $\mathrm{p}$ value of less $\leq 0.05$ was used to declare significance association between perinatal outcomes and its predictors in the chi-square test. Bivariate logistic regression was done. Variables which were significantly associated with perinatal outcomes in bivariate logistic regressions were included in the multiple logistic regressions.

Result: adverse perinatal outcome was 5.9 times higher in mother who had unplanned pregnancy (AOR: 5.9(2.16, 16.16),3.48 times higher among mother who did not received iron during pregnancy(AOR: 3.48( 1.24, 9.73) and, 5 times higher risk in mother with history of chronic hypertension (AOR: 5.11(1.98, 13.17) .In contrast, the risk was (AOR: 0.33(.17, .62) and (AOR: $0.43(.22, .87)$ lower among mother who were urban residence and who had term birth.

Conclusion: Special emphasis should be givento women whose residence is rural, who have unplanned pregnancy, preterm birth and women with history of chronic hypertension and iron supplement were identified as protective factor to adverse pregnancy outcomes.

Keywords: Preinatal out comes, Determinates, Southwest, Ethiopia 


\section{Introduction}

\subsection{Background}

Perinatal outcomes refer to life events that occur to the newborn infant from the age of viability ( 28 weeks) to the first week of life. The transition of a fetus immersed in the amniotic fluid to life outside the womb is not always smooth and can result in adverse events to the mother or the baby. Perinatal outcomes vary from pregnancy to pregnancy which includes; normal live birth, low birth weight, prematurity in the baby, stillbirth, intrauterine fetal death, early neonatal death and late neonatal death. Adverse perinatal outcomes are those pregnancy outcomes other than normal live birth which majorly includes preterm birth, stillbirth and low birth weight which are the major cause of neonatal morbidity, mortality and long term physical and psychological problems (1-3).

Adverse perinatal outcomes are common health problems in developing countries and incur significant health consequences on infants, and emotional and economic costs on families, and communities across the world, particularly in resource-limited settings where health systems and access to and utilization of health services are weak(2-6).

The etiology of perinatal death is often unknown and depends on the quality of health care given to the pregnant women and their newborn, but can be attributable to different factors and the most common factor in developing countries were residence, educational status, occupation, hypertensive disorders of pregnancy, gestational age, place of delivery, parity, history of Perinatal death, ANC, history of abortion, mal-presentation, number of antenatal cares and an obstetric complication(7-9)

Among maternal medical problem, pregnancy induced hypertension (PIH) remains one of the top five causes of maternal and perinatal mortality worldwide. pre-eclampsia is responsible for more than 500,000 of preinatal death, this is equivalent to the loss of 1600 lives per day; more than $99 \%$ of these losses occur in low- and middle-income countries (LMIC), particularly in subSaharan Africa(SSA) (10, 11). Almost half of neonatal mortality can be prevented through tetanus toxoid vaccine (TTV), clean and skilled care at the birth, newborn resuscitation, exclusive breastfeeding, clean umbilical cord care, and management of infections 
in the newborns(8). Therefore the aim of this study is to examine determinants of adverse perinatal outcome at selected governmental hospitals in southwest Ethiopia.

\section{Methods and materials}

2.1. Study setting and design. This study was done using data from three selected governmental Hospital found in southwest Ethiopia. Facility based unmatched case control study design was carried out from May5 to June15, 2021.The data was collected through interview by considering COVID-19 prevention protocol. This study included all pregnant women who were seeking delivery services at selected hospitals during the study period. Babies delivered before 28 weeks of gestation, mothers whose age was different from15-49 years old, mothers whose charts are unavailable during data collection, mother who gave two or more babies were excluded from the study.

\subsection{Data collection tools and procedures}

Data about study variables was collected through face to face interviews using structured questionnaires and prepared checklists .Data collection was conducted by three midwives and supervision of the data collection process was managed by investigators. Midwives who were working in the delivery wards of selected facilities were recruited for data collection to manage logistics related issues. The data collection was carried out in line with COVID-19 prevention protocol. The Ethiopian demographic and health survey (EDHS) questionnaires were adapted to measure socioeconomic and demographic, obstetrics and gynaecological characteristics of the study participants. The study tool was translated to Amharic language and then translated back to the English language to check consistency. Clients' medical record was reviewed to confirm the diagnosis, previous medical and gynaecological conditions of the study participants.

\subsection{Data analysis}

The data was entered in a template prepared on Epi-Data manager version 4.4.2.1. Data cleaning was done by running frequencies and cross-tabulating with the main outcome variables. Missing values were checked against hard copies of the collected data to correct it accordingly. The data was exported to SPSS version 23 for analysis. Threshold pvalue of less $\leq 0.05$ was used to declare significance association between perinatal outcomesand its predictors in the chi-square test. Bivariate logistic regressions were done. Hence, variables which were found to be associated with perinatal outcome were included in the multiple logistic regressions. Multi- 
collinearity between independent variables was checked. The Hosmer-Lemeshow goodness of fit test was used to assess the fitness of the final model.

\subsection{Operational definitions}

Adverse perinatal outcomes refer to life events that occur to the newborn from the age of viability (28 weeks) to the first 8 hours of life (LBW, preterm, stillbirth, neonatal death (10-13) Low birth weight the weight of the newborn $<2.5 \mathrm{~kg}(14,15)$.

Preterm birth is a birth before a gestational age of 37 completed weeks(16).

Stillbirth: Stillbirth is a baby born with no signs of life at or after 28 weeks' gestation (8). Neonatal death the death of baby with in 8 hours of birth

\subsection{Ethical considerations}

Ethical clearance and letter of approval was obtained from the Mizan Aman Health Science College (MAHSC), Research Ethics Committee (REC). A letter of permission was obtained from administrative bodies of the selected hospital and was given to the selected ward case team coordinators. The purpose of the study was explained and informed consent was obtained from each study participant before data collection. Confidentiality of information received from the study participants was managed by using codes rather than using the name of participants during data collection. Participants was informed that participation is fully voluntary and so that they can stop the participation at any stage of the interview if they do not want to continue

\section{Result}

\section{Participant's socio-demographic characteristics}

A total of 310 respondents were included in the study with cases to control ratio of 1:2(103 cases and 207controls). Age of participant ranged from 15 to 49 years with median ageof17and standard deviationof \pm 9 . Thirty\%participantswereaged between 20-24years,94 (41.61\%)of the study participants was aged 25-29 years,and7\% were aged at least 35years. Marital status of the majority192 (92.75\%) controls and $85(82.52 \%)$ cases were married whereas, the rest16 (7.24\%) controls\&18 (16.50\%) cases were not married, either unmarried, living together, widowed or divorced. Concerning residence 130 (41.93\%) of participant were rural resident of participantwhowereruralresident130 $(48.46 \%)$ of their birth outcome were adverse perinatal outcome while from urban residents 200 (20\%) their birth outcome adverse perinatal outcome. 
Regarding education, 59 (58.28\%) of cases and 135 (65.21) controls can read \&write 44 $(42.71 \%)$ and72 (34.79\%) of cases and controls respectively can not read and write whereas, 50 (24.16) controls and 38 (36.90) cases of participants husband respectively can not to read and write .Occupation, 31(30\%) of cases and 69 (33.33\%) controls were housewife. On the other hand, $7(6.79 \%)$ and $37(17.9 \%)$ of cases and controls respectively involve private business. Income, $31(30 \%)$ of cases and $56(27 \%)$ controls earns less than one thousand Ethiopian birr. In the same manner, $25(24.27 \%)$ and $55(26.55 \%)$ of cases and controls respectively earn four thousand Ethiopian birr or more. with regards to family size, $51(49.5 \%)$ of cases and $88(42.5 \%)$ controls had three or less families whereas, 52 (50.48\%) and $119(57.48 \%)$ of cases and controls respectively had four or more families. The socio-demographic characteristics of study participants are presented prissily below in the table1

Table1: Socio-demographic characteristics of participant, in selected governmental Hospitals of Southwest Ethiopia, 2021(n=310)

\begin{tabular}{|c|c|c|c|c|}
\hline Variables & Controls (\%) & Cases (\%) & $\mathrm{X}^{2}$ & $\mathrm{P}$ value \\
\hline Mother age(years) & & & 21 & .000 \\
\hline $15-19$ & $10(4.83)$ & $20(19.41)$ & & \\
\hline $20-24$ & $67(32.36)$ & $27(26.21)$ & & \\
\hline $25-29$ & $94(45.41)$ & $35(33.98)$ & & \\
\hline $30-34$ & $25(12.07)$ & $10(9.70)$ & & \\
\hline$\geq 35$ & $11(5.37)$ & $11(10.67)$ & & \\
\hline Marital status & & & 12 & 0.016 \\
\hline Married & 192(92.75) & $85(82.52)$ & & \\
\hline Unmarried & $2(0.96)$ & $6(5.82)$ & & \\
\hline Living together & $12(5.8)$ & $9(8.73)$ & & \\
\hline Divorced & $1(0.48)$ & $1(0.97)$ & & \\
\hline Widowed & $0(0)$ & $2(1.94)$ & & \\
\hline Residence & & & 23.4 & 0.000 \\
\hline Urban & $140(68.96)$ & $40(38.83)$ & & \\
\hline Rural & $67(31.04)$ & $63(61.17)$ & & \\
\hline Education( read\& write) & & & 1.85 & .17 \\
\hline Yes & $135(65.21)$ & $59(57.28)$ & & \\
\hline No & $72(34.79)$ & $44(42.71)$ & & \\
\hline Source of income & & & 6.7 & 0.08 \\
\hline mother herself & $5(2.41)$ & $7(6.79)$ & & \\
\hline Husband & $87(42.02)$ & $52(58.48)$ & & \\
\hline husband \& mother & $110(53.14)$ & $42(40.77)$ & & \\
\hline Other & $5(2.41)$ & $2(1.94)$ & & \\
\hline Husband can read \& write & & & 5.5 & 0.019 \\
\hline
\end{tabular}




\begin{tabular}{|c|c|c|c|c|}
\hline $\begin{array}{l}\text { Yes } \\
\text { No }\end{array}$ & $\begin{array}{c}157(75.84) \\
50(24.16)\end{array}$ & $\begin{array}{l}65(63.10) \\
38(36.90)\end{array}$ & & \\
\hline Occupation & & & 13.7 & 0.056 \\
\hline Housewife & $69(33.33)$ & $31(30.09)$ & & \\
\hline Student & $21(10.14)$ & $15(14.56)$ & & \\
\hline Daily labourer & $15(7.24)$ & 11(10.67) & & \\
\hline Private business & $37(17.87)$ & $7(6.79)$ & & \\
\hline Government employee & $26(12.56)$ & $20(19.41)$ & & \\
\hline Farmer & 33(15.94) & $19(18.44)$ & & \\
\hline Hand-craft worker & $4(1.93)$ & $0(0)$ & & \\
\hline Others & $2(0.96)$ & $0(0)$ & & \\
\hline Income & & & 2.10 & 0.56 \\
\hline$<1000$ & $56(27)$ & $31(30)$ & & \\
\hline $1001-2000$ & $42(20.28)$ & $19(18.44)$ & & \\
\hline 2001-3000 & $23(11.11)$ & $17(16.50)$ & & \\
\hline $3001-4000$ & $31(14.97)$ & $11(10.67)$ & & \\
\hline$\geq 4001$ & $55(26.55)$ & $25(24.27)$ & & \\
\hline Family size & & & .136 & .24 \\
\hline $1-3$ & $88(42.51)$ & $51(49.51)$ & & \\
\hline$\geq 3$ & $119(57.48)$ & $52(50.48)$ & & \\
\hline
\end{tabular}

Bivariable analysis of risk factors on adverse perinatal outcome

In bivariable analysis, Mother age, Residence, source of income, Educational status of the mother, Husband ability to read \& write, Planned pregnancy, Gestation of pregnancy, Number of ANC visits, Iron supplement, History of CHTN and PIH were significantly associated with perinatal outcome(Table2).

Binary logistic regression analysis revealed that mothers whose age at least 25 years were at .07 times less risk for adverse perinatal outcome than those mothers who aged 35 and above years $(\mathrm{COR}=.072,95 \% \mathrm{CI}:(.14-.93)$. With respect to marital status mothers who were living together were found to be at risk to develop risk of adverse perinatal outcome compared with those who had married. The odds of developing adverse perinatal outcome was found to be 2.7 times higher among mother living together compared with married mother (COR: 2.7, 95\% CI: 2.71, 5.63). Those mothers who were urban resident were 0.30 times less at risk to have adverse perinatal outcome than those who were rural resident $(\mathrm{COR}=0.30,95 \%$ CI: $(0.86$, 0.49). Similarly source of income a had significantly associated with having of adverse perinatal outcome, mother who earn income herself and husband were 0.28 times less likely to have 
adverse perinatal outcome than mother who earn income by herself $(\mathrm{COR}=.28,95 \% \mathrm{CI}:(.0 .8$, .90). Husband ability to read \&write were also associated with having of adverse perinatal outcome, mother whose husband can not to read \&write were 18.8 times at higher risk of having adverse perinatal outcome compared with mother whose husband can read \&write $(\mathrm{COR}=18.8$, 95\%CI: (110.3, 06).

Bivariable analysis also shows that the odds of developing adverse perinatal outcomes was found to be 2.25times higher among women who had unplanned pregnancy compared with those who had planned pregnancy (COR: 2.25, 95\% CI :( 1.05, 4.8). More over mother who had preterm birth was at higher risk to had adverse perinatal outcome, the risk of adverse perinatal outcome among mother whose birth is preterm were2.22 times higher risk to have adverse perinatal outcome compared to that term birth (COR 2.22, 95\% CI $(1.377,3.59$.) . Antenatal care , mothers who had less than two ANC were at higher risk to haveadverse perinatal outcome, mothers who had less than two ANC were3times more likely to have adverse perinatal outcome than mother who have three and more ANC (COR: 3, 95\% CI :( 1.64-5.65) Likewise, women who did not receiving iron during pregnancy was found to be a statistically significant risk factor for having adverse perinatal outcome, mother who did not received iron during pregnancy were 2.47 times at risk of having adverse perinatal outcome than mother who received iron (COR: 2.47, 95\%CI: $(1.47,4.32)$.And those mother who had history of chronic hypertension were 2.53times more at risk to have adverse perinatal outcome than those who had no family history of chronic hypertension (COR: 2.53, 95\% CI :( $1.25,5.10)$.

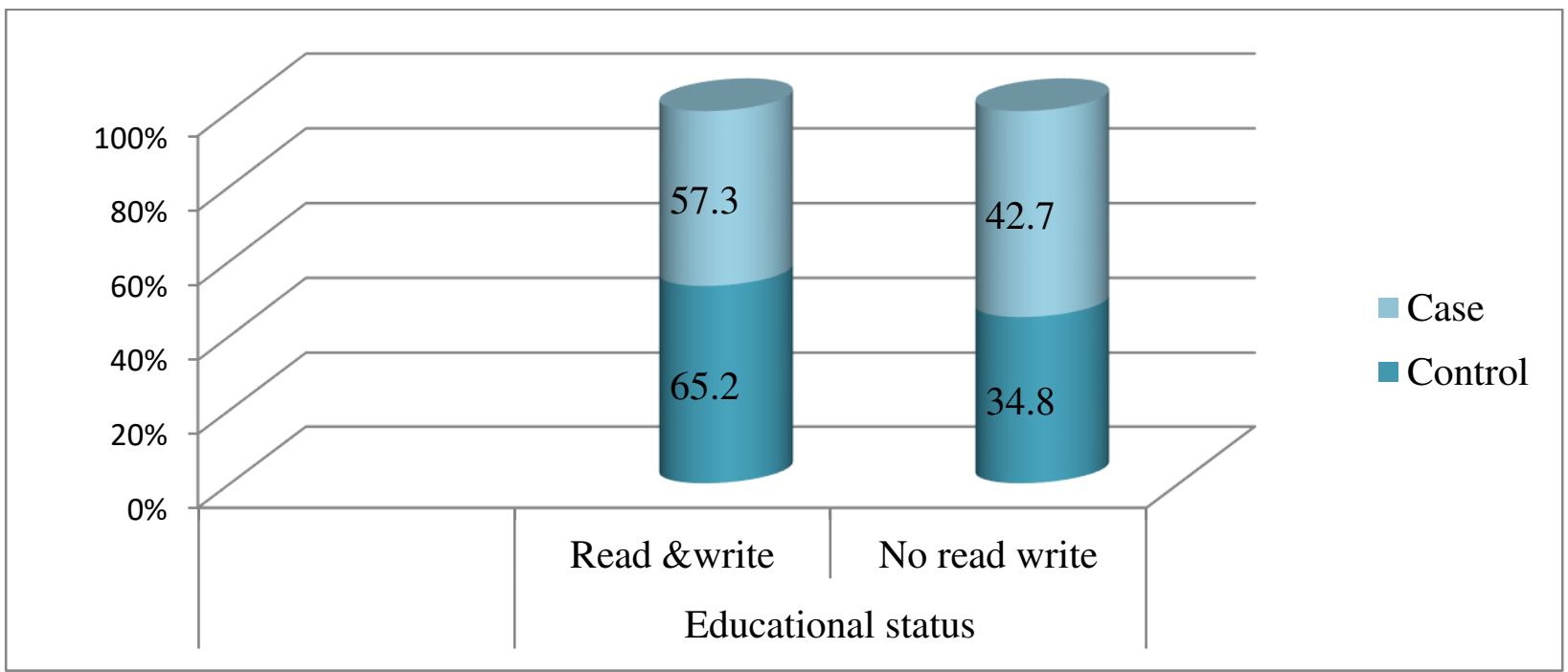


Figure 1: educational status women who gave birth, in selected governmental Hospitals of Southwest Ethiopia, 2021

Educational status, $57.3 \%$ of cases and $65.2 \%$ of controls were reported as they have the ability to read and write

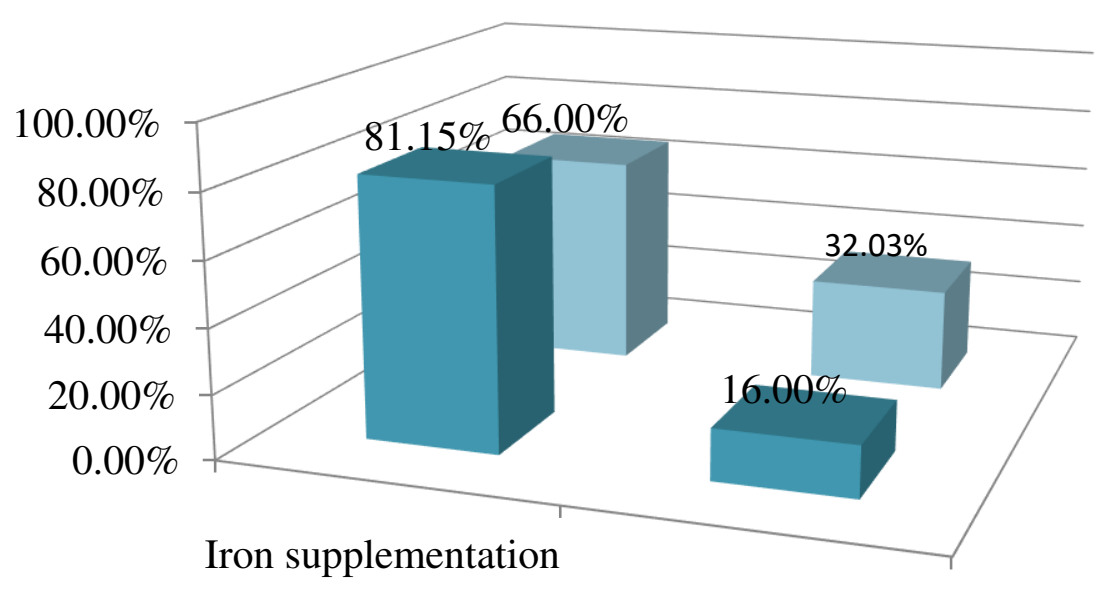

Control

Case

Figure 2: women who supplemented iron during pregnancy in selected governmental Hospitals of Southwest Ethiopia, 2021

Iron supplementation was found to be low among cases compared with controls. Of the total respondents who had iron supplemented, 236(28.8\%) \& 66(50\%) women were iron supplemented among controls and cases respective

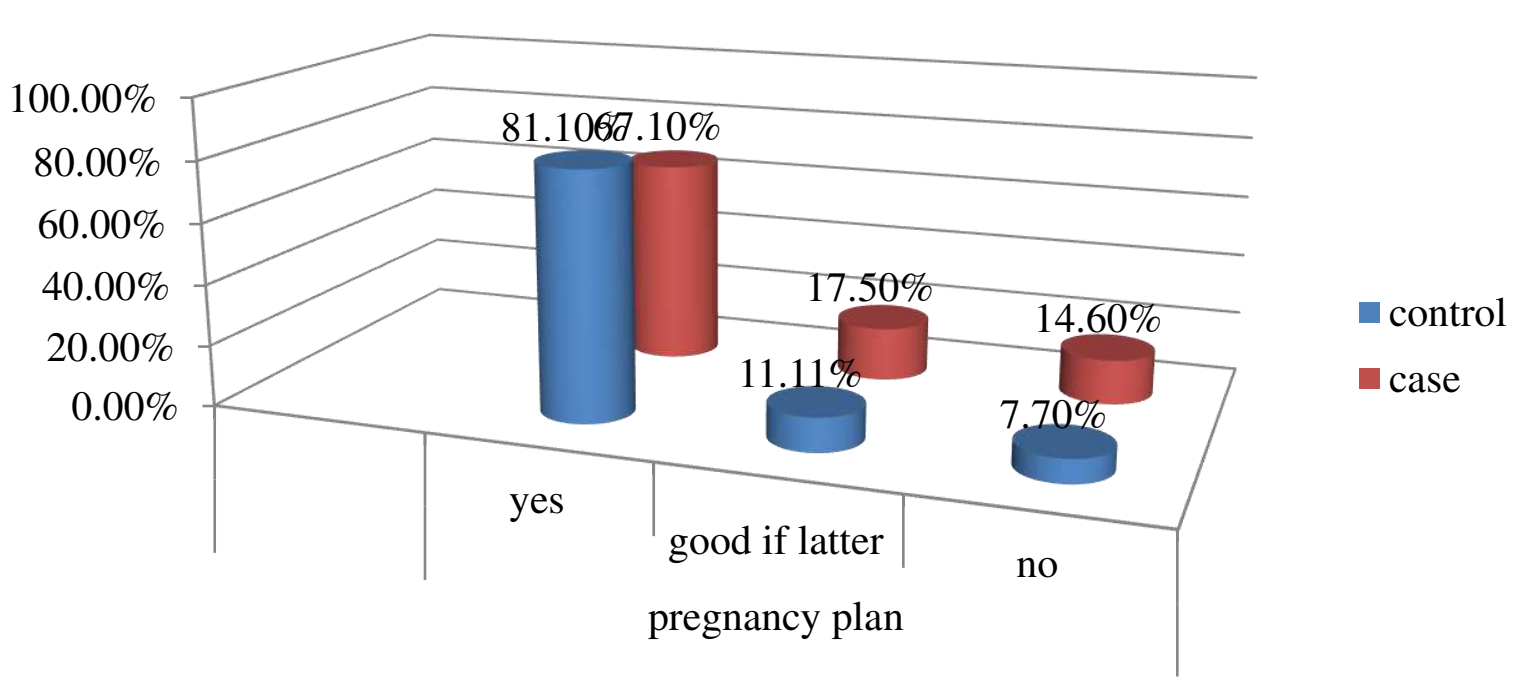


Figure 3: women intention of pregnancy in selected governmental Hospitals of Southwest Ethiopia, 2021

Planned pregnancy was found to be high among controls compared with cases. From the total respondents who had unplanned pregnancy, 15(48.4\%) had adverse perinatal outcome

Table 2: Bivariable analysis of risk factors on determinants of adverse perinatal outcome among women who gave birth, in selected governmental Hospitals of Southwest Ethiopia, 2021(n=310)

\begin{tabular}{|c|c|c|c|c|}
\hline Variables & Controls (\%) & Cases $(\%)$ & COR $(95 \% \mathrm{CI})$ & $\mathrm{P}$ value \\
\hline \multicolumn{5}{|l|}{ Mother age(years) } \\
\hline $15-19$ & $10(4.83)$ & $20(19.41)$ & $2(.64,6.18)$ & \multirow{5}{*}{.036} \\
\hline $20-24$ & $67(32.36)$ & $27(26.21)$ & $.40(.156,1.04)$ & \\
\hline $25-29$ & $94(45.41)$ & $35(33.98)$ & $.072(.14, .93)$ & \\
\hline $30-34$ & $25(12.07)$ & $10(9.70)$ & $.4(.132,1.21)$ & \\
\hline$\geq 35$ & $11(5.37)$ & $11(10.67)$ & 1 & \\
\hline \multicolumn{5}{|l|}{ Marital status } \\
\hline Married & 192(92.75) & $85(82.52)$ & 1 & \multirow[b]{2}{*}{.008} \\
\hline Unmarried & $15(7.25)$ & $18(17.48)$ & $2.71(1.30,5.63)$ & \\
\hline \multicolumn{5}{|l|}{ Residence } \\
\hline Urban & $140(68.96)$ & $40(38.83)$ & 1 & \multirow[t]{2}{*}{.000} \\
\hline Rural & $67(31.04)$ & $63(61.17)$ & $3.29(2.013,5.381)$ & \\
\hline \multicolumn{5}{|c|}{ Education( read\& write) } \\
\hline Yes & $135(65.21)$ & $59(57.28)$ & 1 & \multirow[b]{2}{*}{.0 .17} \\
\hline No & $72(34.79)$ & $44(42.71)$ & $1.3(.86,2.26)$ & \\
\hline \multicolumn{5}{|l|}{ Source of income } \\
\hline mother herself & $5(2.41)$ & $7(6.79)$ & 1 & \multirow[b]{3}{*}{.034} \\
\hline Husband & $87(42.02)$ & $52(58.48)$ & $.42(.12,1.41)$ & \\
\hline husband \& mother & $110(53.14)$ & $42(40.77)$ & $.27(.08, .90)$ & \\
\hline Other & $5(2.41)$ & $2(1.94)$ & $.28(0.3,2.1)$ & \\
\hline \multicolumn{5}{|c|}{ Husband can read \&write } \\
\hline Yes & $157(75.84)$ & $65(63.10)$ & 1 & \multirow[b]{2}{*}{.020} \\
\hline No & $50(24.16)$ & $38(36.90)$ & $18.83(1.10,3.06)$ & \\
\hline \multicolumn{5}{|l|}{ Planned pregnancy } \\
\hline Yes by then & $168(81.15)$ & $70(67.96)$ & 1 & \\
\hline good if latter & $23(11.11)$ & $18(17.47)$ & $1.87(.95,3.69)$ & \\
\hline No & $16(7.72)$ & $15(14.56)$ & $2.25(1.05 .4 .80)$ & .036 \\
\hline \multicolumn{5}{|l|}{ Gestation of pregnancy } \\
\hline$<37$ weeks & $76(36.71)$ & $58(56.31)$ & $0.45(.27, .72)$ & \multirow[t]{2}{*}{.001} \\
\hline$\geq 38$ weeks & $131(63.29)$ & $45(43.69)$ & 1 & \\
\hline \multicolumn{5}{|l|}{ No of ANC visits } \\
\hline $1-2$ & $(2513.66)$ & $28(32.55)$ & $3(1.64,5.65)$ & \multirow[t]{2}{*}{.000} \\
\hline$\geq 3$ & $158(.33)$ & $58(67.44)$ & 1 & \\
\hline \multicolumn{5}{|l|}{ Iron supplement } \\
\hline Yes & $168(81.15)$ & $68(66.01)$ & 1 & \\
\hline
\end{tabular}




\begin{tabular}{lcccc}
\hline No & $33(15.94)$ & $33(32.03)$ & $2.47(1.41,4.32)$ & .001 \\
History of CHTN & $90(91.78)$ & $84(81.55)$ & 1 & \\
No & $17(8.21)$ & $19(18.44)$ & $2.53(1.25,5.10)$ & .010 \\
Yes & & & \\
PIH & $200(96.62)$ & $90(87.33)$ & 1 & \\
No & $7(3.38)$ & $13(12.62)$ & $4.12(1.59,10.69)$ & .004 \\
Yes &
\end{tabular}

ANC: antenatal care, GA: gestational age, CHTN: chronic hypertension, PIH, pregnancy induced hypertension,

Multivariable logistic regression analysis of risk factors on determinants of adverse perinatal outcome: Table (3) showed about analysis which was done on medical, obstetric and sociodemographic factors within cases and controls. The variation among cases and controls were analyzed in binary logistic regression, after that a variable which was statistically significant within binary logistic regression were entered into multivariable logistic regression analysis to establish the determinants of adverse perinatal outcome. In multiple logistic regression analysis residence, pregnancy plan, iron supplement, gestation of pregnancy and history of CHTN were significantly associated with adverse perinatal outcome as clearly depicted in (Table3)

Living in rural areas was statistically significant risk factor for adverse perinatal outcomes. The multivariable analysis showed that mothers who were urban residents were 0.33 times at less risk to have adverse perinatal outcomes than mothers who were rural residents (AOR: 0.33, 95\%,CI: $.17, .62)$. Plan of pregnancy was also found to be independently associated with adverse perinatal outcomes in multiple logistic regressions. The odds of having adverse perinatal outcome were found to be higher in mothers who had unplanned pregnancy than mother who had planned pregnancy (AOR: 5.9, 95\%,CI: $(2.16,16.16)$. Likewise, multiple logistic regressions showed that the risk of having adverse perinatal outcomes was impacted by iron supplementation during pregnancy. Mothers who did not have iron supplements were3.48 times at higher risk to have adverse perinatal outcomes compared to mothers who had iron supplements (AOR:3.48,95\%CI: $(1.24,9.73)$.Mothers who had history of HTN were5times at higher risk of having adverse perinatal outcome compared to with mothers who had no history of HTN (AOR: 5.11 95\%,CI: 1.98, 13.17). Preterm birth increased risk of having of adverse perinatal outcome. Mothers who had term birth were $57 \%$ less likely to have of adverse perinatal outcome than mothers who had preterm birth (AOR: 0.4395\%, CI: .22, .87). 
Table3: Multivariable logistic regression analysis risk factors on determinants of perinatal outcome among women who gave birth, in selected governmental Hospitals of Southwest Ethiopia, 2021(n=310).

\begin{tabular}{|c|c|c|c|c|c|}
\hline Variables & Cases (\%)n & Control(\%n & COR $(95 \% \mathrm{CI})$ & AOR $(95 \% \mathrm{CI}$ & P value \\
\hline \multicolumn{6}{|l|}{ Residence } \\
\hline Urban & 192(92.75) & $85(82.52)$ & 1 & 1 & \\
\hline Rural & $15(7.25)$ & $18(17.48)$ & $0.30(0.18,0.49)$ & $0.33(.17, .62)$ & .001 \\
\hline \multicolumn{6}{|l|}{ Pregnancy plan } \\
\hline Yes by then & $168(81.15)$ & $70(67.96)$ & 1 & 1 & .002 \\
\hline Good if latter & 23(11.11) & 18(17.47) & $1.87(.95-3.69)$ & $5.90(2.16,1)$ & \\
\hline No & $16(7.72)$ & $15(14.56)$ & $2.25(1.05,4.80)$ & $4.58(.8,25)$ & . \\
\hline \multicolumn{6}{|l|}{ Iron supplement } \\
\hline Yes & $168(81.15)$ & $68(66)$ & 1 & 1 & \\
\hline No & $33(15.94)$ & $33(32.03)$ & $2.47(1.41-4.32)$ & $3.48(1.24,9.73)$ & .017 \\
\hline \multicolumn{6}{|l|}{ CHTN } \\
\hline Yes & $90(91.78)$ & $84(81.55)$ & $2.53(1.25-5.10)$ & $5.11(1.98,13.17)$ & .001 \\
\hline No & $17(8.21)$ & 19(18.44) & 1 & 1 & \\
\hline $\begin{array}{l}\text { Gestation } \\
\text { of pregnancy }\end{array}$ & & & & & .221 \\
\hline$<37$ weeks & $76(36.71)$ & $58(56.31)$ & $0.45(.27, .72)$ & $0.43(.22, .87)$ & .019 \\
\hline$\geq 38$ weeks & $131(63.29)$ & 45(43.69) & 1 & 1 & \\
\hline
\end{tabular}

CHTN: chronic hypertension, **Percentage is calculated from column total

\section{Discussion}

This study indicates that the determinants of adverse perinatal outcome among women who gave birth in selected governmental Hospitals of Southwest Ethiopia. To the beast of our knowledge there is no study on determinants of adverse preinatal outcome in southwest Ethiopia. Rural residence were at increased risk of adverse perinatal outcome, the other core finding were plane of pregnancy, which was significant associated with reduced risk of adverse perinatal outcome during the study period, we also appreciate thatthere is significant reduced risk of having adverse perinatal outcome among women who gave birth at term and women who received iron during pregnancy in multivariable analysis.

In multivariable analysis place of residence was found to be a risk factor for havingadverse perinatal outcome .Mother who live in urban were.33 times less likely to have adverse perinatal outcome than mother who live in rural .This finding is in agreement with study done in Gamogofa however, lower than study done in sub-Saharan Africa and the discrepancy may be 
due to socio cultural difference $(17,18)$. Likewise, Mothers who had plans for pregnancy were found to be at lower risk to have adverse perinatal outcomes compared to those mothers who had unplanned pregnancy. The odds of adverse perinatal outcome were 4.58times higher for mothers who had unplanned pregnancy. This odd of adverse perinatal outcome was higher than study done in Tigry (19).Iron during pregnancy was found to be a statistically significant risk factor for having adverse perinatal outcome in this research. The odds of having adverse perinatal outcome were found to be 3.48 times higher among mothers who did not iron supplements than mothers who received iron during pregnancy ,this finding is supported by studies done before (20, 21).Havingadverse perinatal outcome was also impacted by the history of HTN.Mother who had history of HTN was 5 times at risk to have adverse perinatal outcomes than mother who hadn't history of HTN, this finding result is higher than study done in AA and other study done in subSaharan Africa $(17,22)$. The disagreement might be due to study setting and, health care utilization behaviour of the mothers for observed higher adverse perinatal outcome.We also in this study found that gestation of pregnancy was the other risk factor for having of adverse perinatal outcome, and mothers who had term birth were $57 \%$ less likely risk of adverse perinatal outcome compared to mothers who had preterm birth the finding is in line with research conducted in Axumdespite, is lower than research done in India and in contrast with research done in Vietnam (23-25)

\section{Strength and Limitation of the study \\ 5.1. Strength of the Study}

Involving study subjects, cases and controls within the same hospital. Unavailable data on records that may have impact on the dependent variable was obtained by interview it could avoid missing data. Examining the effect of multiple risk factors of adverse perinatal outcome

\subsection{Limitation of the study}

The data may possibly expose to recall bias and participants may not share the original characteristics therefore social desirability bias is unavoidable. Diagnostic experiences variation of physician

\section{Conclusion and Recommendation}

\subsection{Conclusion}

In conclusion, this study identify that low birth weight was the highest among adverse pregnancy outcomes and on the other hand, stillbirth was the second most adverse birth outcome followed by preterm birth from births takes place in selected hospitals of southwest Ethiopia in 2021. This study also indicates that there are different risk factors for adverse perinatal outcome. Rural residence, unplanned pregnancy, preterm birth, history of HTN were identified risk and ironssupplements was identified as protective factor to adverse pregnancy outcomes 


\subsection{Recommendation}

This research indicates factors associated with adverse perinatal outcome may be used to prevent adverse perinatal outcome.

The following recommendations are suggested based on the finding of our study which provides a chance for prevention of adverse perinatal outcome.Pregnant women particularly living in rural should have access for maternal health service and contraception and iron shall be strengthens

\section{Declaration}

\section{Ethical approval}

Ethical approval was obtained from the Mizan Aman Health Science College, Research Ethics Committee. And, (Project. 0062021/approved 07 May 2021). Consent was. Obtained from each study participant before data collection. Consent for publication was done Data and materials are available with Corresponding author

\section{Competing interests}

The authors declare that we have no competing interests.

\section{Funding}

Mizan-Aman Health Science College

Authors' contributions

ISRAEL DEREKIYAB ' MELESE TEBEKA ,TEREFE KETO ' conceived the study and contributed to the design, analysis and interpretation of the study.All authors read and approved the final version of the manuscript

Principal investigator/corresponding author MELESE TEBEKA

Acknowledgments

We would like to thank Mizan-Aman Health Science College for financing the study

Author details

ISRAELDEREKIYAB (MPH) ${ }^{1}$

TEREFE KETO (Bsc) $(\mathrm{MPH})^{1 *}$

MELESE TEBEKA $(\mathrm{MPH})^{1 *}$

1 Department of Public Health, Mizan-Aman Health Science College, Southwest Ethiopia E-mail: acohs@ethionet.et

\section{Abbreviation}

$\begin{array}{ll}\text { ANC } & \text { Antenatal Care } \\ \text { APH } & \text { Ante Partum Haemorrhage } \\ \text { APO } & \text { Adverse Perinatal Outcome } \\ \text { CHTN } & \text { Chronic hypertension } \\ \text { EMONC } & \text { Emergency Obstetric and Newborn Care } \\ \text { EDHS } & \text { Ethiopia Demographic and Health Survey } \\ \text { ENAP } & \text { Every Newborn Action Plan } \\ \text { EWEC } & \text { Every Women and Every Child Health } \\ \text { GTS GH } & \text { Gebre-Tsadik Shawo General Hospital } \\ \text { IUFD } & \text { Intrauterine Fetal Death }\end{array}$




$\begin{array}{ll}\text { IUGR } & \text { Intrauterine Fetal Growth Restriction } \\ \text { LBW } & \text { Low Birth Weight } \\ \text { LMIC } & \text { Low- and Middle-Income Countries } \\ \text { MACHS } & \text { Mizan Aman College Health Science } \\ \text { M TUT } & \text { Mizan Tepi-University Teaching Hospital } \\ \text { PPH } & \text { Postpartum Haemorrhage } \\ \text { PIH } & \text { Pregnancy Induced Hypertension } \\ \text { PROM } & \text { Premature Rupture of Membrane } \\ \text { REC } & \text { Research Ethics Committee } \\ \text { SGA } & \text { Small for Gestational Age } \\ \text { SNNPRS } & \text { South Nation Nationality People Regional State } \\ \text { TTV } & \text { Tetanus Toxoid Vaccine }\end{array}$

\section{References}

1. Yeshialem E, Abera M, Tesfay A. Determinants of adverse pregnancy outcomes among mothers who gave birth from jan 1-dec 31/2015 in jimma university specialized hospital, case control study, 2016. Ethiopian Journal of Reproductive Health. 2019;11(1):10-.

2. Lee AC, Katz J, Blencowe H, Cousens S, Kozuki N, Vogel JP, et al. National and regional estimates of term and preterm babies born small for gestational age in 138 low-income and middle-income countries in 2010. The Lancet Global Health. 2013;1(1):e26-e36.

3. Kassahun EA, Mitku HD, Getu MA. Adverse birth outcomes and its associated factors among women who delivered in North Wollo zone, northeast Ethiopia: a facility based crosssectional study. BMC Research Notes. 2019;12(1):1-6.

4. Hornstra G, Uauy R, Yang X. The impact of maternal nutrition on the offspring: Karger Medical and Scientific Publishers; 2005.

5. Kramer MS. The epidemiology of adverse pregnancy outcomes: an overview. The Journal of nutrition. 2003;133(5):1592S-6S.

6. You D, Hug L, Ejdemyr S, Idele P, Hogan D, Mathers C, et al. Global, regional, and national levels and trends in under-5 mortality between 1990 and 2015, with scenario-based projections to 2030: a systematic analysis by the UN Inter-agency Group for Child Mortality Estimation. The Lancet. 2015;386(10010):2275-86.

7. Wolde Z, Segni H, Woldie M. Hypertensive disorders of pregnancy in Jimma University specialized hospital. Ethiopian journal of health sciences. 2011;21(3).

8. Lassi ZS, Bhutta ZA. Community-based intervention packages for reducing maternal and neonatal morbidity and mortality and improving neonatal outcomes. Cochrane database of systematic reviews. 2015(3).

9. Vogel JP, Souza J, Mori R, Morisaki N, Lumbiganon P, Laopaiboon M, et al. Maternal complications and perinatal mortality: findings of the World Health Organization Multicountry Survey on Maternal and Newborn Health. BJOG: An International Journal of Obstetrics \& Gynaecology. 2014;121:76-88.

10. Aminu M, Unkels R, Mdegela M, Utz B, Adaji S, Van Den Broek N. Causes of and factors associated with stillbirth in low-and middle-income countries: a systematic literature review. BJOG: An International Journal of Obstetrics \& Gynaecology. 2014;121:141-53. 
11. Hockenberry MJ, Wilson D. Wong's nursing care of infants and children-E-book: Elsevier Health Sciences; 2018.

12. Bililign Yimer N, Tenaw Z, Solomon K, Mulatu T. Inadequate prenatal visit and home delivery as determinants of perinatal outcomes: does parity matter? Journal of pregnancy. 2019;2019.

13. Abdo R, Endalemaw T, Tesso F. Prevalence and associated factors of adverse birth outcomes among women attended maternity ward at Negest Elene Mohammed Memorial General Hospital in Hosanna Town, SNNPR, Ethiopia. J Women's Health Care. 2016;5(4):1000324.

14. Vogel J, Souza J, Mori R, Morisaki N, Lumbiganon P, Laopaiboon M. Erratum: Maternal complications and perinatal mortality: Findings of the World Health Organization Multicountry Survey on Maternal and Newborn Health (BJOG: An International Journal of Obstetrics and Gynaecology (2014) 121). BJOG: an International Journal of Obstetrics and Gynaecology. 2015;122(3):451-.

15. Bayou G, Berhan Y. Perinatal mortality and associated risk factors: a case control study. Ethiopian journal of health sciences. 2012;22(3).

16. Newtonraj A, Kaur M, Gupta M, Kumar R. Level, causes, and risk factors of stillbirth: a population-based case control study from Chandigarh, India. BMC pregnancy and childbirth. 2017;17(1):1-9.

17. Olusanya BO, Ofovwe GE. Predictors of preterm births and low birthweight in an innercity hospital in sub-Saharan Africa. Maternal and child health journal. 2010;14(6):978-86.

18. Gebremeskel F, Gultie T, Kejela G, Hailu D, Workneh Y. Determinants of adverse birth outcome among mothers who gave birth at hospitals in Gamo Gofa zone, southern Ethiopia: a facility based case control study. Qual Prim Care. 2017;25(5):259-66.

19. Hailemichael HT, Debelew GT, Alema HB, Weldu MG, Misgina KH. Determinants of adverse birth outcome in Tigrai region, North Ethiopia: Hospital-based case-control study. BMC pediatrics. 2020;20(1):1-9.

20. Newcombe HB. Risk of Fetal Death to Mothers of Different ABO and Rh Blood Type. American journal of human genetics. 1963;15(4):449.

21. Hassan KK. ABO Blood Groups Compatibility and Incompatibility among Basrah Families.

22. Mulu GB, Gebremichael B, Desta KW, Kebede MA, Aynalem YA, Getahun MB. Determinants of low birth weight among newborns delivered in public hospitals in Addis Ababa, Ethiopia: Case-control study. Pediatric health, medicine and therapeutics. 2020;11:119.

23. Berhe AK, Ilesanmi AO, Aimakhu CO, Mulugeta A. Effect of pregnancy induced hypertension on adverse perinatal outcomes in Tigray regional state, Ethiopia: a prospective cohort study. BMC pregnancy and childbirth. 2020;20(1):1-11.

24. Graner S, Klingberg-Allvin M, Phuc HD, Huong DL, Krantz G, Mogren I. Adverse perinatal and neonatal outcomes and their determinants in rural Vietnam 1999-2005. Paediatric and perinatal epidemiology. 2010;24(6):535-45.

25. Delnord M, Blondel B, Prunet C, Zeitlin J. Are risk factors for preterm and early-term live singleton birth the same? A population-based study in France. BMJ open. 2018;8(1):e018745. 